\title{
ANALISA PERBEDAAN TIPE POST, PERIODE POST DAN PROMOSI TERHADAP ONLINE ENGAGEMENT DI INSTAGRAM LITTLE STU
}

\author{
Ferdy Mahendra \\ Program Studi Magister Manajemen Universitas Tarumanagara \\ ferdy.mahendra@gmail.com \\ Suwinto Johan \\ Program Studi Magister Manajemen Universitas Tarumanagara \\ Masuk : 04-11-2020, revisi : 17-12-2020 diterima untuk diterbitkan : 18-12-2020
}

\begin{abstract}
This study aims to analyze differences in post types, post periods, and promotions on online engagement on Little Stu's Instagram account. The design in this study is a descriptive research design with historical data types carried out during the period July 2020 September 2020. The data collection method is from the insta story screen shot uploaded by Little Stu's Instagram account then recorded manually in a periodic time. The population in this study were Little Stu's Instagram account followers who saw the insta story as a viewer and gave comments on the insta story's content. The number of insta story samples selected was 906 posts. The data analysis technique used in this study is the Kruskal-Wallis test or commonly referred to as the non-parametric one-way ANOVA test where the Kruskal-Wallis test is a ranking-based test that can be used to see any statistically significant differences between two or more groups that have characteristics continuous or ordinal processed using SPSS. The results showed that there were significant differences between the types of posts on the number of viewers and comments, there was a significant difference between the period of posts on the number of viewers and comments, there was no significant difference between promotions on the number of viewers but there was a significant difference between promotions and the number of comments.
\end{abstract}

Keywords: Post Type, Post Period, Promotion, Online Engagement

\begin{abstract}
Abstrak: Penelitian ini bertujuan untuk menganalisis perbedaan tipe post, periode post, dan promosi terhadap online engagement di akun Instagram Little Stu. Desain dalam penelitian ini adalah desain penelitian deskriptif dengan jenis data historis yang dilakukan selama periode Juli 2020 - September 2020. Cara pengumpulan datanya adalah dari screen shot insta story yang diunggah akun Instagram Little Stu kemudian dicatat secara manual dalam waktu berkala. Populasi dalam penelitian ini adalah followers akun Instagram Little Stu yang melihat insta story sebagai viewer dan memberikan komentar atas konten insta story tersebut. Jumlah sampel insta story yang dipilih adalah sebanyak 906 post. Teknik analisis data yang digunakan dalam penelitian ini adalah uji Kruskal -Wallis atau biasa disebut dengan uji ANOVA satu arah non parametrik dimana uji Kruskal-Wallis adalah uji berbasis peringkat yang dapat digunakan untuk melihat adanya perbedaan signifikan secara statistik antara dua kelompok atau lebih yang memiliki sifat kontinu atau ordinal yang diolah menggunakan SPSS. Hasil penelitian menunjukkan bahwa terdapat perbedaan yang signifikan antara tipe post terhadap jumlah viewer dan komentar, terdapat perbedaan yang signifikan antara periode post terhadap jumlah viewer dan komentasr, tidak ada perbedaan yang signifikan antara promosi terhadap jumlah viewer tetapi ada perbedaan yang signifikan antara promosi terhadap jumlah komentar.
\end{abstract}

Kata Kunci: Tipe Post, Periode Post, Promosi, Online Engagement 


\section{PENDAHULUAN}

Bisnis online berdiri ini awalnya karena pemilik memiliki banyak waktu luang di sela mengurus anak dan ingin mencoba peruntungan dengan berbisnis namun hanya memiliki modal yang terbatas sehingga belum mampu untuk memulai bisnis besar. Usaha pakaian anak dipilih karena pemilik ingin menjawab permasalahan ibu-ibu dimana pakaian anak sering kali hanya dipakai beberapa kali dan tidak cukup lagi karena perkembangan anak 1-6 tahun sangatlah pesat sedangkan harga pakaian anak bisa dikatakan lebih mahal dari pakaian orang dewasa. Hal ini juga didukung oleh perilaku yang berubah ketika wanita menjadi seorang ibu, hal yang menjadi pride dan kebanggaan seorang ibu adalah putra putrinya, maka media sosial mereka akan dipenuhi oleh foto-foto putra putrinya. Diawali dengan naluri alami tersebut, ibuibu muda tersebut semakin senang mendadani putra putrinya sehingga menjadi trendy dan bergaya.

Media sosial adalah tempat atau wadah dimana seseorang atau sebuah merek mendeskripsikan bahkan membentuk opini publik agar dilihat oleh pelanggan, itulah mengapa penting untuk membahas dampak suatu post terhadap online engagement. Oleh karena hal tersebut, perlu adanya penelitian yang bisa mendukung merek, terutama UKM di sektor tertentu, untuk memanfaatkan media sosial terutama Instagram agar bisa meraih online engagement secara optimal. Penelitian ini memberikan kontribusi berupa alternatif solusi untuk mengangkat keputusan manajerial dalam memilih konten post dan promosi, yaitu tipe post dan tipe promosi serta periode waktu post dan periode waktu promosi yang banyak menarik konsumen terutama untuk UKM/online shop.

Dari semua jenis media sosial yang ada, penggunaan Instagram telah digunakan oleh jutaan user yang aktif menggunakan media sosial. Menurut data yang dirilis napoleoncat.com, pada periode Januari-Mei 2020, pengguna Instagram di Indonesia mencapai 69,2 juta pengguna.

Berdasarkan latar belakang yang telah dibahas, maka masalah yang diangkat pada penelitian ini adalah online shop belum mengetahui konten post dan promosi yang paling membentuk online engagement secara optimal, untuk itu penulis tertarik untuk meneliti hal ini dengan judul penelitian "Analisa Perbedaan Tipe Post, Periode Post dan Promosi Terhadap Online Engagement di Instagram Little Stu”.

\section{Tujuan Penelitian}

1. Menganalisa perbedaan tipe post (collection, sharing question, model references) terhadap online engagement (viewer) konsumen Little Stu di Instagram.

2. Menganalisa perbedaan tipe post (collection, sharing question, model references) terhadap online engagement (komentar) konsumen Little Stu di Instagram.

3. Menganalisa perbedaan periode post (hari) terhadap online engagement (viewer) konsumen Little Stu di Instagram.

4. Menganalisa perbedaan periode post (hari) terhadap online engagement (komentar) konsumen Little Stu di Instagram.

5. Menganalisa perbedaan periode post (tanggal) terhadap online engagement (viewer) konsumen Little Stu di Instagram.

6. Menganalisa perbedaan periode post (tanggal) terhadap online engagement (komentar) konsumen Little Stu di Instagram.

7. Menganalisa perbedaan promosi (potongan harga dan bundling package) terhadap online engagement (viewer) konsumen Little Stu di Instagram.

8. Menganalisa perbedaan promosi (potongan harga dan bundling package) terhadap online engagement (komentar) konsumen Little Stu di Instagram. 


\section{TELAAH PUSTAKA}

\section{Tipe Post}

Post merupakan artikel yang diunggah ke halaman website/media sosial berupa kata, gambar, maupun video. Kegiatan mengunggah post ke dalam media sosial maupun website bisa disebut dengan post. Sebuah konten post penting diperhatikan untuk membangun online engagement. Menurut McGurk (2014), konsumen akan tersambung dan terikat dengan suatu merek di media sosial jika terdapat sesuatu yang berarti di dalam post bagi konsumen. Pada penelitian ini terdapat tiga tipe post yang akan digunakan, yaitu mengenai collection, sharing question, dan model references.

\section{Promosi}

Menurut Kotler dan Armstrong (2018) dalam bukunya mengemukakan, "Promotion. Developing and spreading persuasive communications about an offer.". Sedangkan pengertian promosi menurut Gitosudarmo (2014) adalah merupakan kegiatan yang ditujukan untuk mempengaruhi konsumen agar mereka dapat menjadi kenal akan produk yang ditawarkan oleh perusahaan kepada mereka yang kemudian mereka menjadi senang lalu membeli produk tersebut.

\section{Online Engagement}

Online engagement menurut Bonson dan Ratkai (2013) bisa didefinisikan sebagai kondisi psikologis dari user yang dikategorikan oleh keinteraktifan, pengalaman kokreatif user dengan seorang agen dan objek. Secara sederhana, engagement merupakan interaksi antara dua orang atau atau lebih terhadap merek di media sosial.

\section{Kaitan antar variabel}

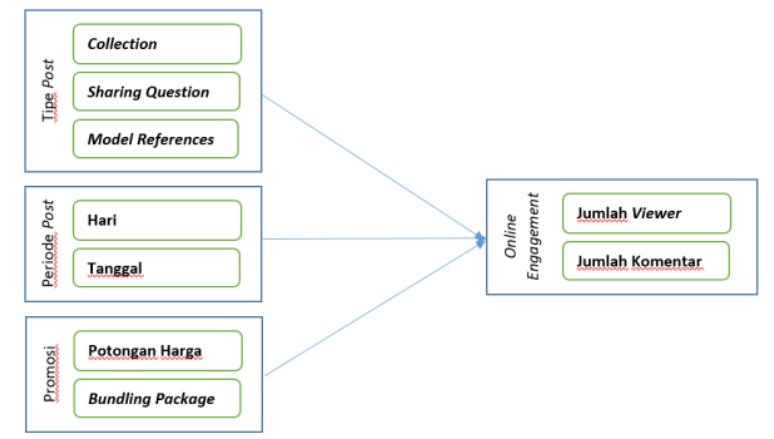

Gambar 1

\section{Model Penelitian}

H11: Terdapat perbedaan jumlah viewer antara Tipe Post berbeda yang diunggah Instagram Little Stu.

H12: Terdapat perbedaan jumlah komentar antara Tipe Post berbeda yang diunggah Instagram Little Stu.

H13: Terdapat perbedaan jumlah viewer antara Hari berbeda yang diunggah Instagram Little Stu.

H14: Terdapat perbedaan jumlah komentar antara Hari berbeda yang diunggah Instagram Little Stu.

H15: Terdapat perbedaan jumlah viewer antara Tanggal berbeda yang diunggah Instagram Little Stu.

H16: Terdapat perbedaan jumlah komentar antara Tanggal berbeda yang diunggah Instagram Little Stu.

H17: Terdapat perbedaan jumlah viewer antara Promosi berbeda yang diunggah Instagram Little Stu.

H18: Terdapat perbedaan jumlah komentar antara Promosi berbeda yang diunggah Instagram Little Stu. 


\section{METODOLOGI PENELITIAN}

Penelitian ini menggunakan data historis yaitu seluruh insta story yang diunggah oleh objek penelitian (akun Instagram Little Stu) dalam kurun waktu 3 bulan, terhitung semenjak Juli 2020 sampai September 2020. Data dalam rentang waktu tersebut digunakan karena bisa mewakili bulan dalam satu kuarter di dalam satu tahun kalender masehi. Sumber data dalam penelitian ini adalah konsumen atau followers yang ada di akun Instagram Little Stu yang melihat insta story Little Stu setiap harinya dan bisa dideskripsikan sebagai viewer dan pemberi komentar atas konten insta story. Penulis mengamati setiap insta story yang diunggah oleh akun online shop Little Stu dari bulan Juli 2020 hingga September 2020. Kemudian penulis mencatat jumlah viewer, komentar dan unsur-unsur konten serta promosi di setiap insta story akun Instagram secara manual dalam waktu berkala. Selain itu penulis juga mengumpulkan data mengenai periode setiap Little Stu mengunggah insta story. Dan semua bukti datanya terkumpul di dalam screenshot insta story yang diatur sedemikian rupa sehingga datanya dapat digunakan dengan baik.

\section{ANALISA DATA DAN PEMBAHASAN}

Jumlah sampel insta story yang dipilih adalah sebanyak 906 post. Teknik analisis data yang digunakan dalam penelitian ini adalah uji Kruskal-Wallis atau biasa disebut dengan uji ANOVA satu arah non parametrik yang diolah menggunakan SPSS.

Hasil Uji perbedaan tipe Post terhadap jumlah viewer yang diunggah Instagram Little Stu (H1). Uji hipotesis pertama yaitu untuk mengetahui perbedaan tipe Post terhadap jumlah viewer. Berdasarkan output pada test statistik dengan menggunkan Kruskal-Wallis Test diperoleh nilai Asymp. Sig. Atau signifikansi sebesar 0,011 $(<0,05)$. Dengan demikian maka H11 diterima artinya ada perbedaan yang signifikan antara tipe Post (collection, sharing question, model references) terhadap jumlah Viewer. Maka jumlah Viewer collection, sharing question, model references tidak sama.

Hasil Uji perbedaan tipe Post terhadap jumlah komentar yang diunggah Instagram Little Stu $\left(\mathrm{H}_{2}\right)$. Pengujian hipotesis kedua yaitu untuk mengetahui perbedaan tipe post terhadap jumlah komentar diunggah Instagram Little Stu. Hasil uji Kruskal-Wallis Test antara tipe post dengan jumlah kommentar diperoleh nilai Asymp. Sig. Atau signifikansi sebesar 0,028 $(<0,05)$. Dengan demikian maka $\mathrm{H}_{2} 2$ diterima artinya ada perbedaan yang signifikan antara tipe Post (collection, sharing question, model references) terhadap jumlah komentar. Maka jumlah komentar pada tipe post yang berbeda yaitu collection, sharing question, model references tidak sama.

Hasil Uji perbedaan Periode Post (Hari) terhadap jumlah viewer yang diunggah Instagram Little Stu (H13). Pada Periode Post dibedakan menjadi dua kelompok yaitu berdasarkan hari dan berdasarkan tanggal. Hasil uji Kruskal-Wallis Test antara periode post hari dengan jumlah viewer diperoleh nilai Asymp. Sig. Atau signifikansi sebesar 0,000 $(<0,05)$. Dengan demikian maka $\mathrm{H}_{3}$ diterima artinya ada perbedaan yang signifikan antara periode Post hari (senin, selasa, rabu, kamis, jumat, sabtu dan minggu) terhadap jumlah viewer. Maka jumlah viewer pada periode Post hari (senin, selasa, rabu, kamis, jumat, sabtu dan minggu) tidak sama.

Hasil Uji perbedaan Periode Post (Hari) terhadap jumlah komentar yang diunggah Instagram Little Stu (H14). Berdasarkan hasil uji Kruskal-Wallis Test antara periode post hari dengan jumlah komentar diperoleh nilai Asymp. Sig. Atau signifikansi sebesar 0,008 $(<0,05)$. Dengan demikian maka $\mathrm{H}_{1} 4$ diterima artinya ada perbedaan yang signifikan antara periode Post hari (senin, selasa, rabu, kamis, jumat, sabtu dan minggu) terhadap jumlah komentar. Maka jumlah viewer pada periode Post hari (senin, selasa, rabu, kamis, jumat, sabtu dan minggu) tidak sama.

Hasil Uji perbedaan Periode Post (Tanggal) terhadap jumlah viewer yang diunggah Instagram Little Stu (H15). Hasil uji Kruskal-Wallis Test antara periode post tanggal dengan 
jumlah viewer diperoleh nilai Asymp. Sig. Atau signifikansi sebesar 0,000 $(<0,05)$. Dengan demikian maka $\mathrm{H}_{5}$ diterima artinya ada perbedaan yang signifikan antara periode Post tanggal (1-31) terhadap jumlah viewer. Maka jumlah viewer pada periode Post tanggal (1-31) tidak sama.

Hasil Uji perbedaan Periode Post (Tanggal) terhadap jumlah Komentar yang diunggah Instagram Little Stu (H16). Hasil uji Kruskal-Wallis Test antara periode post tanggal dengan jumlah komentar diperoleh nilai Asymp. Sig. Atau signifikansi sebesar 0,000 $(<0,05)$. Dengan demikian maka $\mathrm{H}_{16}$ diterima artinya ada perbedaan yang signifikan antara periode Post tanggal (1-31) terhadap jumlah komentar. Maka jumlah komentar pada periode Post tanggal (1-31) tidak sama.

Hasil Uji perbedaan Promosi terhadap jumlah viewer yang diunggah Instagram Little Stu $\left(\mathrm{H}_{7}\right)$. Berdasarkan hasil uji Kruskal-Wallis Test antara promosi dengan jumlah Viewer diperoleh nilai Asymp. Sig. Atau signifikansi sebesar 0,845 (>0,05). Dengan demikian maka $\mathrm{H}_{7} 7$ ditolak artinya tidak ada perbedaan yang signifikan antara promosi (tidak ada promosi, potongan harga dan Bundling package) terhadap jumlah Viewer. Maka jumlah viewer pada promosi (tidak ada promosi, potongan harga dan Bundling package) relatif sama.

Hasil Uji perbedaan Promosi terhadap jumlah Komentar yang diunggah Instagram Little Stu (H18). Berdasarkan hasil uji Kruskal-Wallis Test antara promosi dengan jumlah komentar diperoleh nilai Asymp. Sig. Atau signifikansi sebesar 0,005 (>0,05). Dengan demikian maka H18 diterima artinya ada perbedaan yang signifikan antara promosi (tidak ada promosi, potongan harga dan Bundling package) terhadap jumlah komentar. Maka jumlah komentar pada saat promosi (tidak ada promosi, potongan harga dan Bundling package) tidak sama satu sama lain.

\section{KESIMPULAN}

1. Terdapat perbedaan yang signifikan antara tipe Post (collection, sharing question, model references) terhadap jumlah Viewer dengan $\mathrm{P}$ value $0,011(<0,05)$ dan ada perbedaan yang signifikan antara tipe Post (collection, sharing question, model references) terhadap jumlah komentar dengan $0,028 \mathrm{P}$ value $(<0,05)$.

2. Terdapat perbedaan yang signifikan antara periode Post hari (senin, selasa, rabu, kamis, jumat, sabtu dan minggu) terhadap jumlah viewer dengan $P$ value $0,000(<0,05)$ dan ada perbedaan yang signifikan antara periode Post hari (senin, selasa, rabu, kamis, jumat, sabtu dan minggu) terhadap jumlah komentar dengan $\mathrm{P}$ value $0,008(<0,05)$. Selanjutnya terdapat perbedaan yang signifikan antara periode Post tanggal (1-31) terhadap jumlah viewer $\mathrm{P}$ value $0,000(<0,05)$ dan jumlah komentar dengan $\mathrm{P}$ value $0,000(<0,05)$.

3. Tidak ada perbedaan yang signifikan antara promosi (tidak ada promosi, potongan harga dan Bundling package) terhadap jumlah Viewer dengan $\mathrm{P}$ value $0,845(>0,05)$ dan ada perbedaan yang signifikan antara promosi (tidak ada promosi, potongan harga dan Bundling package) terhadap jumlah komentar dengan $\mathrm{P}$ value $0,005(<0,05)$.

\section{SARAN}

1. Saran berdasarkan hasil penelitian adalah online shop Little Stu bisa mengunggah tipe post sharing question lebih sering lagi untuk meningkatkan online engagement.

2. Online shop juga perlu mempertimbangkan hari Rabu sebagai waktu untuk pemposting produk dagangan lebih banyak. Sedangkan hari Jumat berpotensi memproleh online engagement lebih sedikit dibandingkan dengan hari lain.

3. Selain itu online shop dapat mempertimbangkan tanggal muda untuk lebih banyak melakukan posting produk karena perpotensi mendapatkan online engagement lebih banyak.

4. Promosi penjualan yang sebaiknya dilakukan adalah potongan harga karena menghasilkan online engagement lebih banyak terutama jumlah komentar. 


\section{DAFTAR PUSTAKA}

Belair-Gagnon, V. (2018). News on the fly: journalist audience online engagement success as a cultural matching process. sagepub.com/journals-permissions DOI: 10.1177/0163443718813473 journals.sagepub.com/home/mcs.

Bonson, E., \& Ratkai, M. (2013). A Set of Metrics to Assess Stakeholder Engagement and Social Legitimacy on A Corporate Facebook Page. Online Information Review, 787-803.

Dessart, L., Veloutsou, C., \& Morgan-Thomas, A. (2015). Consumer engagement in online brand communities: A social media perspective. Journal of Product \& Brand Management, 24(1), 28-42.

Dolan, R., Conduit, J., Frethey-Bentham, C., Fahy, J., \& Goodman, S. (2019). Social media engagement behavior. European Journal of Marketing.

Gitosudarmo, I. (2014). Manajemen Pemasaran. BPFE Yogyakarta.

Jessica, M.d.B.S., Alencar, S.d.F., Grigg, M.K., Lourdes, M.d.A.B. (2019). Online engagement and the role of digital influencers in product endorsement on instagram. Journal of Relationship Marketing, 1533-2667.

Kotler, P. \& Amstrong, G. (2018). Principles of Marketing (Edisi 15 Global Edition). Pearson.

Lin, Y. F., \& Chiu, Y. P. (2015). Influence of Facebook brand-page posts on online engagement. Online Information Review, 505-519.

Mahayani, O. C, Aknuranda, I., \& Kusyanti, A. (2019). Pengaruh customer engagement melalui media sosial terhadap kepercayaan merek (Studi Kasus: Instagram Shopee). Jurnal Pengembangan Teknologi Informasi dan Ilmu Komputer, 3(4), April 2019, 33013310.

McGurk, S. (2014). What is Social Media Engagament and Why it Matters for your Business. Diakses pada http://blog.fusionfarm.com/what-is-social-media-engagement-and-why-itmatters-for-your-business tanggal 22 September 2020.

Mustafa, I. Pengguna Instagram di Indonesia Didominasi Wanita dan Generasi Milenial. Diakses pada https://www.goodnewsfromindonesia.id/2020/06/14/pengguna-instagramdi-indonesia-didominasi-wanita-dan-generasi

milenial\#: :text=Menurut\%20data\%20yang\%20dirilis\%20Napoleon,(69.270.000)\%20 pengguna tanggal 22 September 2020.

Rohadian, S. (2019). Upaya membangun customer engagement melalui media sosial Instagram. Journal of Entrepreneurship, Management, and Industry (JEMI), 2(4), 179187.

Santoso, A.P., Baihaqi, I., \& Persada, S.F. (2017). Pengaruh post Instagram terhadap online engagement: Studi kasus pada lima merek pakaian wanita. Jurnal Teknik ITS, 6(1). ISSN: 2337-3539.

Thakur, R. (2018). Customer engagement and online reviews. Journal of Retailing and Consumer Services, 41, 48-59.

Vries, L. d., Gensler, S., \& Leeflang, P. S. (2012). Popularity of brand posts on brand fan pages: An investigation of the effects of social media. Journal of Interactive Marketing, 83-91. 